\title{
Dust Emission over Different Land Surface in the Arid Region of Northwest China
}

\author{
Yanbo SHEN, Zhibao SHEN \\ Cold and Arid Regions Environmental and Engineering Research Institute, Chinese Acadmy of Sciences, \\ Lanzhou, China
}

Mingyuan DU

National Institute for Agro-Environmental Science, Tsukuba, Japan

and

Wanfu WANG

The Conservation Institute of Dunhuang Academy, Dunhuang, China

(Manuscript received 9 November 2004, in final form 8 August 2005)

\begin{abstract}
In this paper, the main wind erosion factors influencing dust emission are analyzed by using the observed data from the gobi and oasis sites of ADEC (Aeolian Dust Experiment on Climate impact) Project in Dunhuang station in Northwest China, and the dust emission rate over the two different land surfaces are calculated by using Shao's dust emission model. The results indicate that the threshold friction velocity over the non-ploughed cropland is larger than that over the gobi desert, while after spring ploughing, it is smaller. Dust emission rate over the ploughed cropland is largest, which is hundreds of times larger than that over the gobi desert. Over the non-ploughed cropland, dust emission rate is less than that over the ploughed cropland, but larger than that over the gobi desert, while when the friction velocity is larger than $0.8 \mathrm{~ms}^{-1}$ it is close or equal to that over the ploughed cropland.
\end{abstract}

\section{Introduction}

The arid and semiarid regions in Northwest China are the important source areas of the atmospheric dust aerosol. Zhang et al. (1997) suggested that the dust emitted from Northwest China is about $800 \mathrm{Tg}^{-1}$. Shao et al. (2003) reported that the average (maximum)

Corresponding author and present affiliation: Yanbo Shen, State Key Laboratory of Numerical Modeling for Atmospheric Science and Geophysical Fluid Dynamics (LASG), Institute of Atmospheric Physics, Chinese Academy of Sciences, Beijing, 100029, China.

E-mail: syb@mail.iap.ac.cn

(C) 2005, Meterological Society of Japan total dust emission over northwest Asia is $11.5 \times 10^{6}\left(65.7 \times 10^{6}\right) \mathrm{t} \mathrm{d}^{-1}$. During the dust event period, small soil particles are drifted from the surface and then transported over distances up to thousands of kilometers. Such magnitude of dust particles not only affect atmospheric quality seriously but also lead to soil degradation. Moreover, dust particles from the soil surface are the key components of atmospheric aerosol, and their radiative forcing will influence regional and global climate (Cheng et al. 2002).

The sandy desert and gobi desert in Northwest China have been considered as the primary source of atmospheric dust. However, re- 
cent studies reported that the dry cropland in oasis is also the important dust source (Zhang Hua et al. 2002). According to the results of wind tunnel experiment, Dong et al. (1987) reported that dust emission accelerated by artificial factors is several times, even hundreds of times larger than that by natural factors. In this paper, by using the data observed from the gobi and oasis sites of ADEC project in Dunhuang, some land surface characters and PBL (Planetary Boundary Layer) parameters which play important roles on the dust emission processes are analyzed, and the dust emission rates over different land surfaces during a dust event, which took place on April 13 of 2002, are calculated by using the dust emission model developed by Shao (2001).

\section{Land surface characters of the gobi desert and cropland}

There are two observation sites of ADEC project in Dunhuang, China. One is gobi site $\left(40.04^{\circ} \mathrm{N}, 94.80^{\circ} \mathrm{E}\right)$ located in a flat gobi desert, the other is oasis site $\left(40.18^{\circ} \mathrm{N}, 94.70^{\circ} \mathrm{E}\right)$ situated in the cropland nearby the center of Dunhuang oasis. The ground surface of gobi desert is covered by gravels (about $2-10 \mathrm{~mm}$ in diameter) and removable sand particles. In cropland, cotton is planted from April to October every year and in the other time the soil surface is bare. In 2002, the cropland was ploughed just before April 8. The land surface conditions of gobi site and oasis site (before and after spring plough) are shown in Photo 1, denoted as (a), (b) and (c) respectively. Details about the two sites and the observation systems have been introduced by Du et al. (2002a).

\subsection{Soil particle size distribution}

As shown in Photo 1(b), the soil surface of the cropland before spring ploughing is so hard that there are almost no erodible particles. However, after spring ploughing, the hard layer was destroyed and the soil surface became very loose. In this case, the soil particles (or clods) with the diameter $d>2000 \mu \mathrm{m}$ and between $355 \sim 2000 \mu \mathrm{m}$ are $23 \%$ and $4 \%$ respectively. In the gobi desert, particles with $d>2000 \mu \mathrm{m}$ and between $850 \sim 2000 \mu \mathrm{m}$ are $42 \%$ and $8 \%$ respectively. Figure 1 shows the distributions of fine particles in both sites. It can be seen from this figure that fine particle size distribution in gobi desert is quasi-normal, with the highest mass content about $13 \%$ at $115 \mu \mathrm{m}$, while quite uniform in the ploughed cropland.

According to the partition standard in wind erosion physics, particles with $d<60 \mu \mathrm{m}$ are dust particles and between $60 \sim 2000 \mu \mathrm{m}$ are sand particles, which means that the mass content of dust particles in gobi desert and ploughed cropland are $7 \%$ and $44 \%$ respectively, and sand particles are 51\% and $33 \%$ respectively. With such particle size distributions, the soil types of gobi desert and cropland are sand and loam respectively, which will be considered in the dust emission model of Shao (2001).

\subsection{Soil water content}

Because Dunhuang lies in an arid region with very little precipitation (annual precipitation amount is about $30 \mathrm{~mm}$ ), irrigation turns to be the most important factors influencing surface soil water content. In Dunhuang area there are two times of irrigation for cropland in November and March each year, leading to the higher soil water content in cropland than that in gobi desert. Because there is not surface soil water content data, according to the observed data as shown in Table 1, we assume that soil water content changes with depth linearly and estimate that the surface soil water contents in gobi desert and cropland are $0.02 \mathrm{v} / \mathrm{v}$ and $0.06 \mathrm{v} / \mathrm{v}$ respectively.

\subsection{Vegetation cover}

As shown in Photo 1, there are not vegetation covers in the gobi desert and cropland in April, therefore, the vegetation fractions in the two sites are considered as 0 .

The surface parameters of the gobi desert and ploughed cropland mentioned above are summarized in Table 2, which will be used in the dust emission model for calculating vertical dust flux.

\section{Friction velocity and threshold friction velocity}

\subsection{Friction velocity}

Based on the observed data and MoninObukhov similarity theory, $u_{*}$ is calculated by aerodynamic method (Zhang Qiang et al. 2002):

$$
\frac{k z}{u_{*}} \frac{\partial v}{\partial z}=\phi_{m}
$$



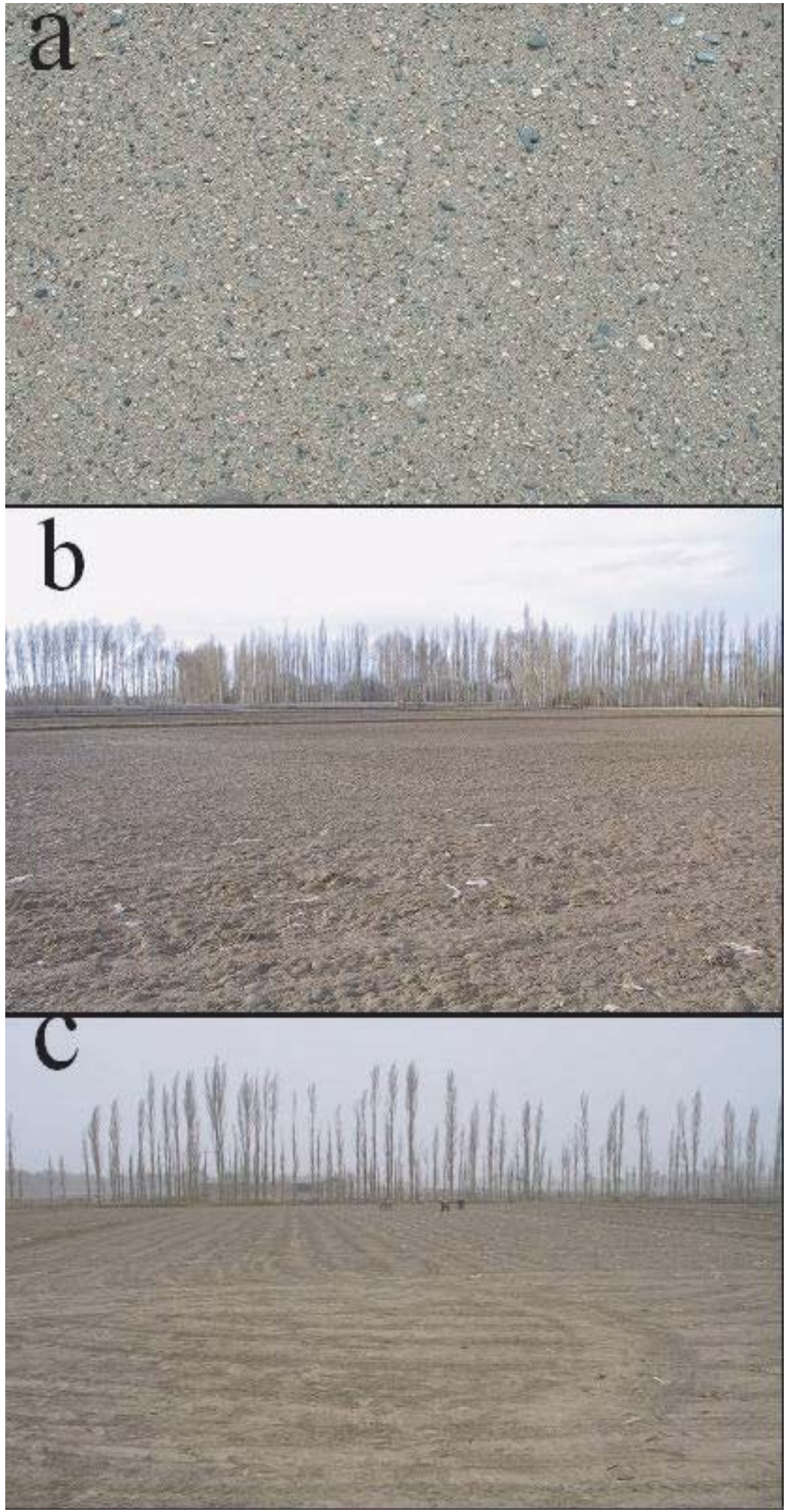

Photo 1. The ground surface conditions: (a) Gobi site, (b) Oasis site before spring plough, (c) Oasis site after spring plough. 

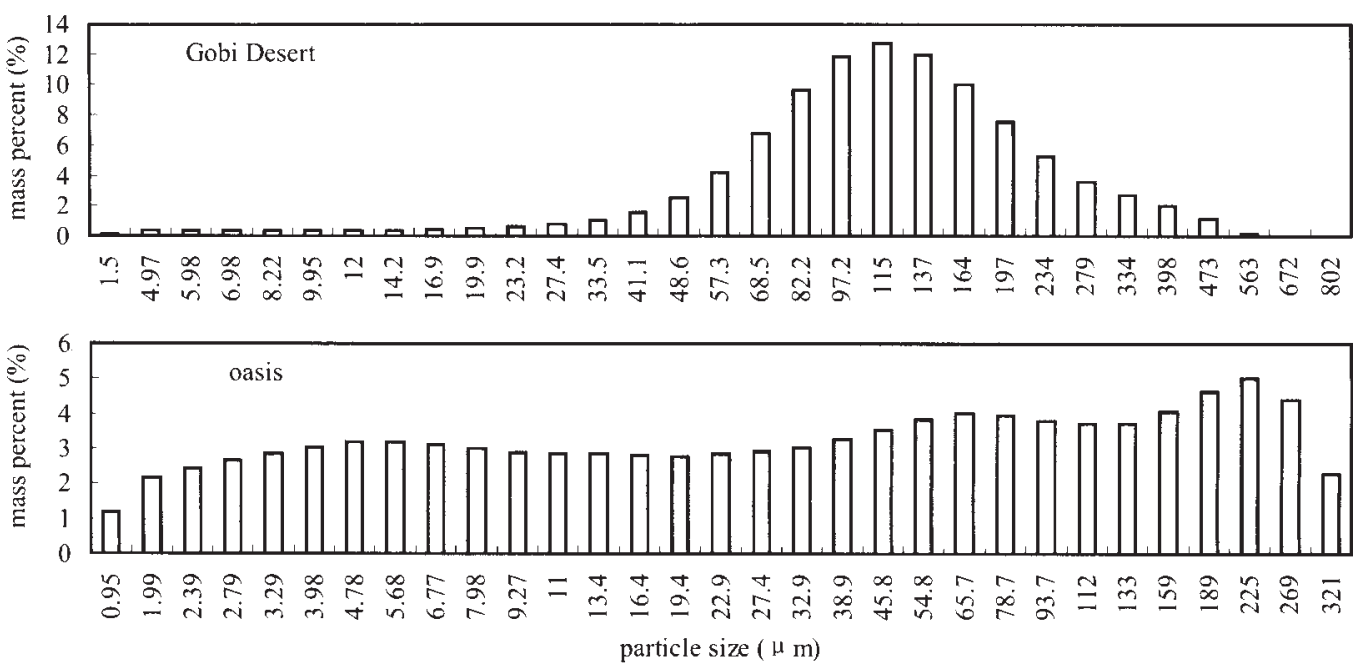

Fig. 1. The distributions of fine particles in gobi desert and ploughed cropland in Dunhuang.

Table 1. Soil water contents (v/v) in the gobi and oasis sites in Dunhuang in April, 2002

\begin{tabular}{lccc}
\hline Site & $\begin{array}{c}20 \mathrm{~cm} \\
\text { (at oasis) } \\
7 \mathrm{~cm}\end{array}$ & $\begin{array}{c}30 \mathrm{~cm} \\
\text { (at oasis) } \\
10 \mathrm{~cm} \\
\text { (estimated) }\end{array}$ & $\begin{array}{c}\text { (at gobi) } \\
\text { (at gobi) }\end{array}$ \\
\hline Oasis & 0.06 & 0.238 & 0.327 \\
Gobi & 0.02 & 0.063 & 0.081 \\
\hline
\end{tabular}

Table 2. The land surface parameters in Gobi and Oasis sites in Dunhuang

\begin{tabular}{lcccc}
\hline & $\begin{array}{c}\text { Soil } \\
\text { water } \\
\text { content } \\
(\mathrm{v} / \mathrm{v})\end{array}$ & $\begin{array}{c}\text { Vegetation } \\
\text { fraction } \\
(\%)\end{array}$ & $\begin{array}{c}\text { Dust } \\
\text { particles } \\
\text { content } \\
(\%)\end{array}$ & $\begin{array}{c}\text { Sand } \\
\text { particles } \\
\text { content } \\
(\%)\end{array}$ \\
\hline Gobi & 0.02 & 0 & 7 & 51 \\
Oasis & 0.06 & 0 & 44 & 33 \\
\hline
\end{tabular}

where $k$ is Karman constant taken to be $0.4 ; v$ is wind velocity at height of $z$, and in this paper, two layers $(4 \mathrm{~m}$ and $1 \mathrm{~m}$ ) of wind velocities are used; $\varphi_{m}$ is Monin-Obukhov similarity function determined by Dyer et al. (1970).

Figure 2 shows the comparison of the $u_{*}$ in gobi desert and cropland during 12:00 20:00 on April 13, 2002. It can be seen from this figure that $u_{*}$ in cropland is very close to that in

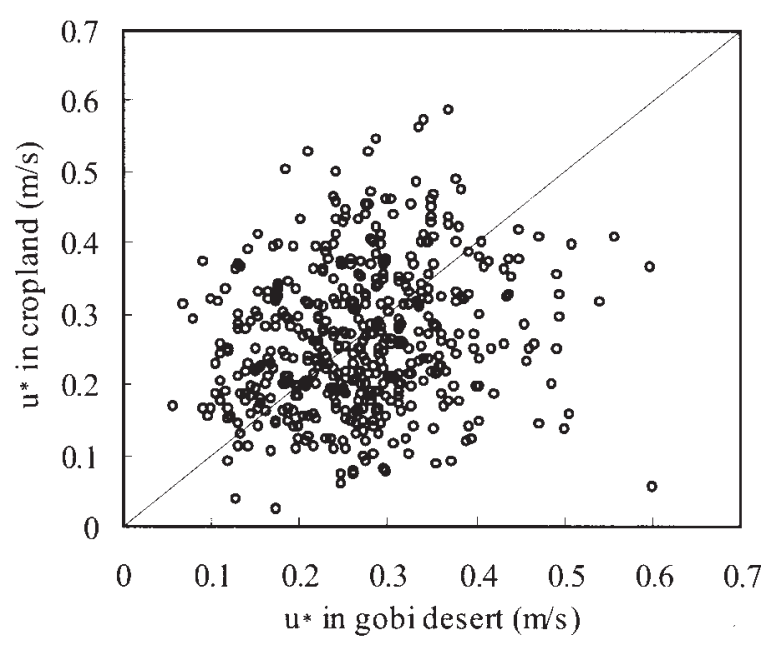

Fig. 2. The comparison of $u_{*}$ in gobi desert and cropland in Dunhuang during 12:00 20:00 on April 13, 2002.

gobi desert, and the average $u_{*}$ in cropland and gobi desert are $0.265 \mathrm{~m} / \mathrm{s}$ and $0.268 \mathrm{~m} / \mathrm{s}$ respectively.

\subsection{Threshold friction velocity}

The threshold friction velocity $u_{* t}$ is calculated by the following formula (Shao et al. 2000):

$$
u_{* t}(d)=H(w) R(\lambda) \sqrt{A_{N}\left(\sigma_{\rho} g d+\frac{\varepsilon}{\rho d}\right)}
$$

where $A_{N}=0.0123$ and $\varepsilon=3 \times 10^{-4} \mathrm{kgs}^{-2}$ are 

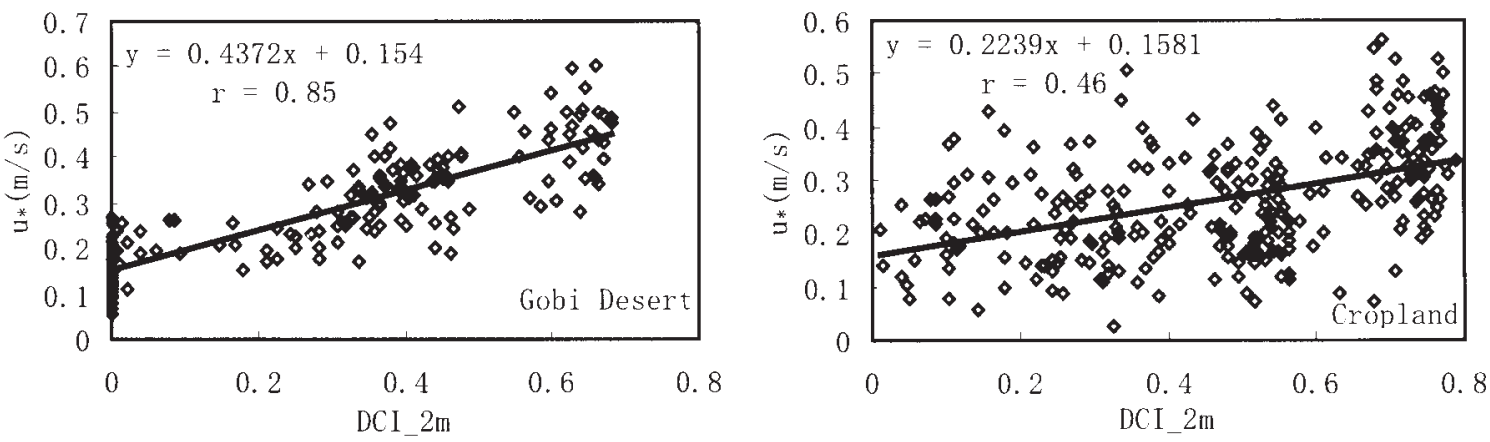

Fig. 3. The correlativity between DCI_2m and $u_{*}$ in gobi desert and cropland on April 13, 2002.

the empirical constant. $\sigma_{\rho}$ is the ratio of the particle density $\left(2650 \mathrm{kgm}^{-3}\right)$ to the air density $\rho\left(1.08 \mathrm{kgm}^{-3}\right.$ at gobi site and $1.11 \mathrm{kgm}^{-3}$ at the oasis site), $d$ is particle diameter and $g$ is gravity acceleration taken to be $9.81 \mathrm{~ms}^{-2}$. The function $R(\lambda)$ that describes the sheltering effect of surface roughness elements is determined by the studies of Raupach et al. (1993). $H(w)$ denotes the influence of surface soil moisture $(w)$ and is estimated from wind tunnel experimental work (Fecan et al. 1999).

The calculated result indicates that $u_{* t}$ in cropland is always larger than that in gobi desert for a given $d$ because of the influence of surface soil water content. On April 13 of 2002, when $d \approx 80 \mu \mathrm{m}, u_{* t}(d)_{\min }$ in gobi desert and cropland are about $0.31 \mathrm{~ms}^{-1}$ and $0.35 \mathrm{~ms}^{-1}$ respectively.

However, it must be pointed out that Eq. (2) is mainly suited for the ground surface without agricultural activities. In 2002, the cropland near the oasis site is ploughed just before April 8. In this case, $u_{* t}$ calculated by Eq. (2) may bring a large error. Therefore, other way should be considered.

In the original observed data from the two sites in Dunhuang, horizontal visibilities at different height are included. However, the visibility sensor is designed to use in fog or haze and the observed maximum visibility is only $1022 \mathrm{~m}$. In order to use these data to reflect dusty weather, Du et al. (2002a) definite a dust concentration index:

$$
\mathrm{DCI}=(a-n) / a
$$

where $a$ is the maximum horizontal visibility, that is $1022 \mathrm{~m}$; $n$ is the instantaneous observed data. DCI indicates relative horizontal visibility and its value is between $0 \sim 1$.

Shen et al. (2003) found that dust particles would be emitted when DCI at height of $2 \mathrm{~m}$ (denotes as DCI_2m) is more than 0.2. Therefore, based on the correlativity between DCI and $u_{*}$ (Fig. 3), it can be estimated that on April 13 of 2002, $u_{* t}$ in the gobi desert and ploughed cropland are about $0.24 \mathrm{~ms}^{-1}$ and $0.20 \mathrm{~ms}^{-1}$ respectively. The former is close to the result from Eq. (2), while the latter is great different from the result from Eq. (2). This fact indicates that $u_{* t}$ in the non-ploughed cropland is larger than that in the gobi desert because of the higher soil water content, and hence dust emission over it will be more difficult. After the spring ploughing, with the hard soil layer of the cropland destroyed entirely, $u_{* t}$ becomes small, even smaller than that in the gobi desert, which will result in dust emission over ploughed cropland being easier than that over gobi desert.

In addition, the hardness of the soil surface is not considered in Eq. (2) either. From Photo 1(b) it can be seen that the cropland before spring ploughing is very hard, and there are even no erodible particles on the surface, therefore, we think that if the hardness was considered, $u_{* t}$ in such surface would be larger than $0.35 \mathrm{~m} / \mathrm{s}$.

\section{Dust emission}

In wind erosion physics, vertical dust flux $F$ is used to indicate the dust emission rate by wind erosion. $F$ is the mass of dust particle in the unit area at certain height parallel with the surface during unit time, and its dimension is $\mathrm{gm}^{-2} \mathrm{~s}^{-1}$ (Shao et al. 1997). In this paper, the 
Gobi desert
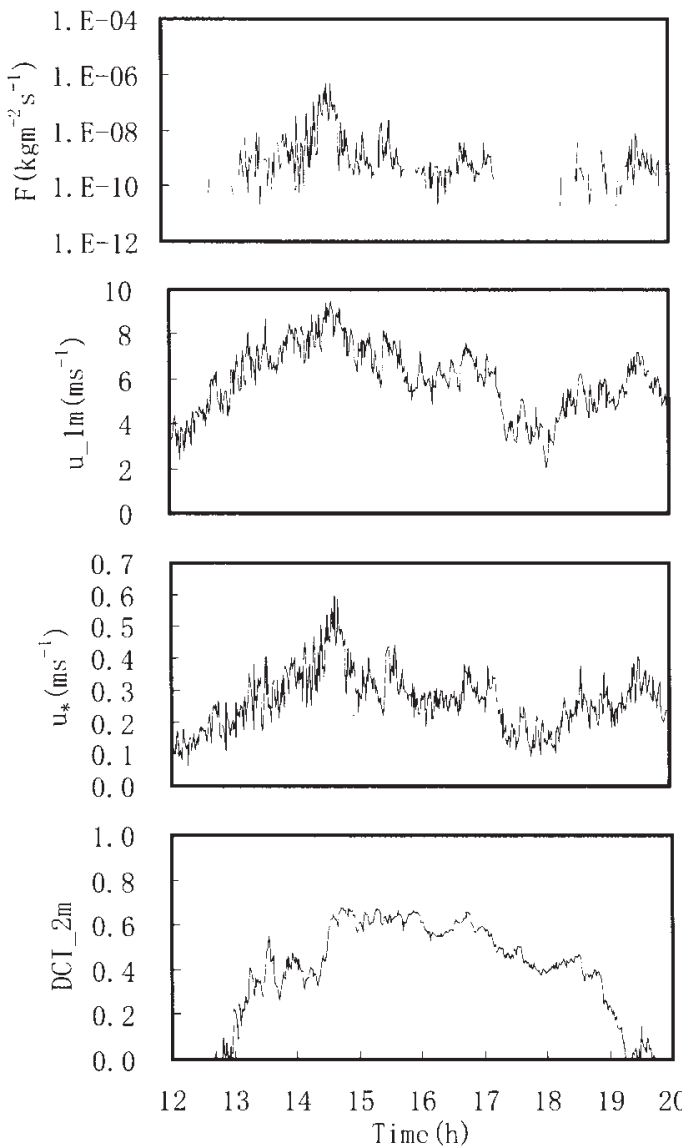

Ploughed cropland
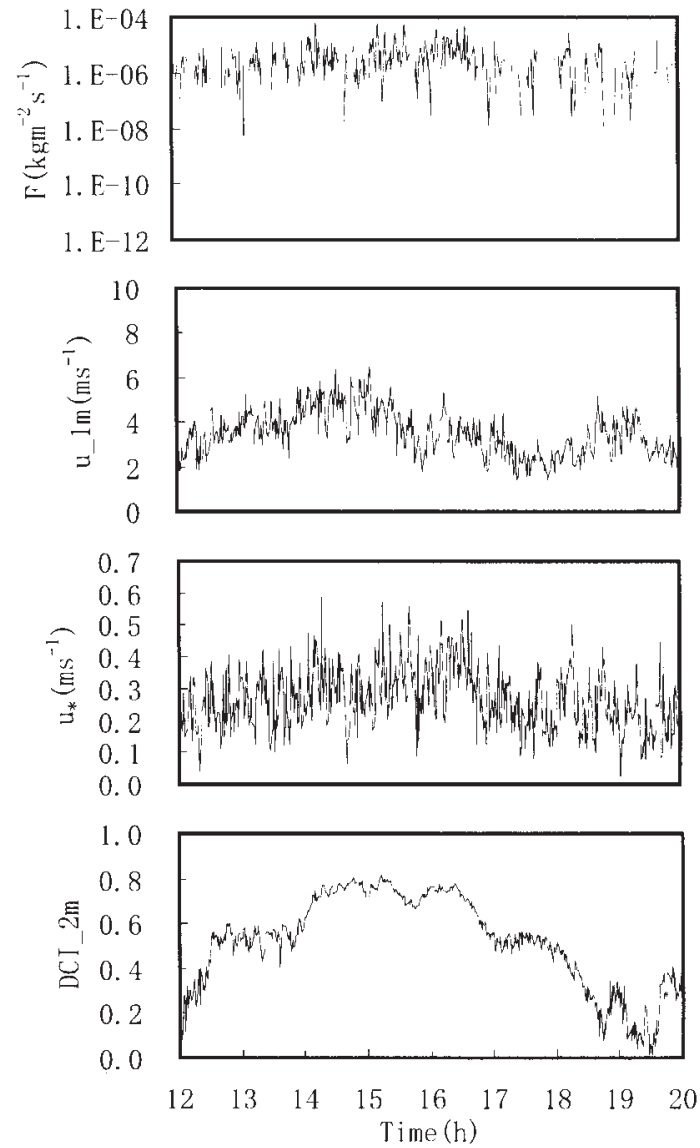

Fig. 4. The variation of $F, u_{-} 1 \mathrm{~m}, u_{*}$ and DCI_2m in the gobi desert and ploughed cropland in Dunhuang during 12:00 20:00 on April 13, 2002.

In the gobi desert, $u_{* t}=0.24 \mathrm{~ms}^{-1}$, and in ploughed cropland, $u_{* t}=0.20 \mathrm{~ms}^{-1}$.

dust emission model developed by Shao (2001) is used to calculate $F$ :

$F_{S}\left(d_{i}, d_{s}\right)$

$=c_{Y}\left[(1-\gamma)+\gamma \frac{p_{m}\left(d_{i}\right)}{p_{f}\left(d_{i}\right)}\right] \frac{Q g}{u_{*}^{2} m}\left(\rho_{b} \eta_{f i} \Omega+\eta_{c i} m\right)$

where $d_{i}$ and $d_{s}$ are diameters of dust particle and sand particle respectively, $c_{Y}$ is empirical constant taken to be $0.05, p_{m}(d)$ and $p_{f}(d)$ are minimally and fully disturbed parent soil particle size distributions respectively, $\gamma$ is the weight for $p_{m}(d)$ and $(1-\gamma)$ is the weight for $p f(d), Q$ is streamwise sand flux, $g$ is gravity acceleration, $m$ is dust particle mass, $\rho_{b}$ is soil bulk density, $\eta_{\beta}$ is total dust fraction in surface soil, $\eta_{c i}$ is dust fraction in aggregation, and $\Omega$ is the volume removal caused by saltation.

According to observation data of DCI, there was a dust event in Dunhuang from 12:00 to 20:00 on April 13 of 2002 (Shen et al. 2003). The variation of $F$ during this period in the gobi desert and ploughed cropland are shown in Fig. 4. At the same time, $u_{*}$ and $u$ at $1 \mathrm{~m}$ (denotes as $\left.u_{-} 1 \mathrm{~m}\right)$ are also shown. From this figure, some results can be got as follows:

(1) The variations of $u_{*}, u \_1 \mathrm{~m}, F$ and DCI_2m are remarkably identical. This fact indicates the reasonability of the observation data and the model.

(2) During this dust event, $u_{*}$ and $u_{-} 1 \mathrm{~m}$ reached peak value gradually and the dust 
Table 3. Simulation results by using different surface soil water content in the gobi desert and cropland

\begin{tabular}{lllllll}
\hline$w(\mathrm{v} / \mathrm{v})$ & Gobi desert & 0.01 & 0.02 & 0.06 & 0.1 & 0.1 \\
& Cropland & 0.01 & 0.02 & 0.06 & 0.3 & 0.3 \\
\hline$u_{* t}\left(\mathrm{~ms}^{-1}\right)$ & Gobi desert & 0.26 & 0.31 & 0.42 & 0.48 & 0.67 \\
& Cropland & 0.25 & 0.25 & 0.35 & 0.71 \\
\hline$F\left(\mathrm{kgm}^{-2} \mathrm{~s}^{-1}\right)$ & Gobi desert & $2.55 \times 10^{-9}$ & $7.52 \times 10^{-10}$ & $2.46 \times 10^{-11}$ & $4.00 \times 10^{-12}$ & 0 \\
& Cropland & $3.66 \times 10^{-6}$ & $3.66 \times 10^{-6}$ & $5.31 \times 10^{-7}$ & $3.00 \times 10^{-8}$ & 0 \\
\hline
\end{tabular}

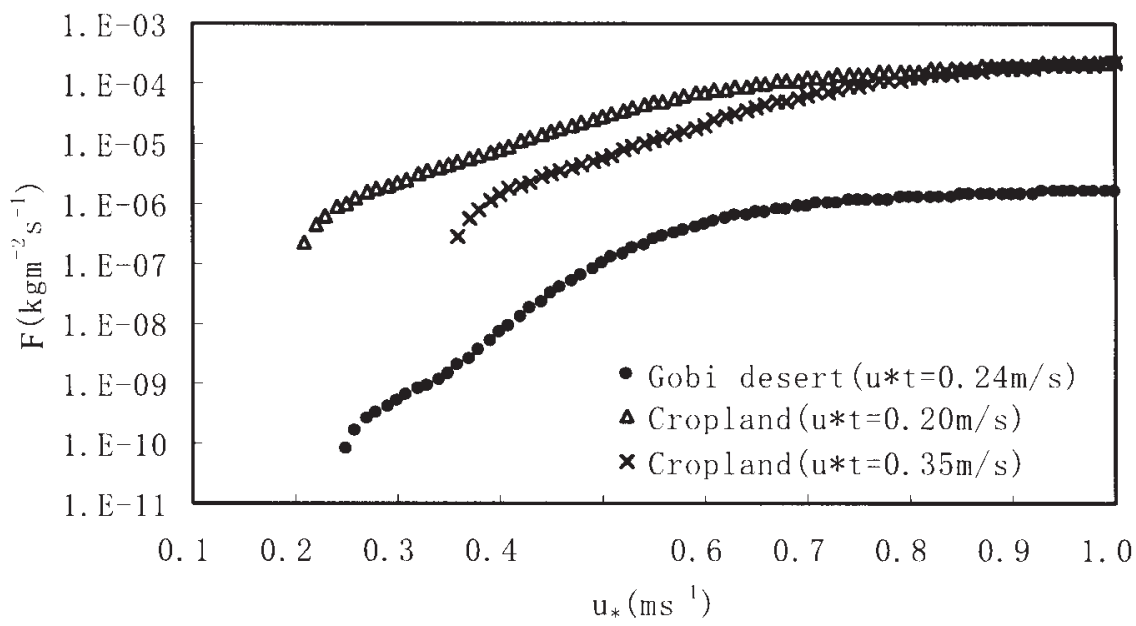

Fig. 5. The variation of vertical dust flux with $u_{*}$ for a given $u_{* t}$ in the gobi desert and cropland.

emission was intense. The average (maximum) $F$ in the gobi desert and ploughed cropland are $6.12 \times 10^{-9}\left(4.54 \times 10^{-7}\right) \mathrm{kgm}^{-2} \mathrm{~s}^{-1}$ and $3.40 \times 10^{-6}\left(6.58 \times 10^{-5}\right) \quad \mathrm{kgm}^{-2} \mathrm{~s}^{-1}$ respectively, and the latter is hundreds of times larger than the former, which results from the smaller $u_{* t}$ and the more dust particle content in ploughed cropland than that in the gobi desert.

\section{Discussions and conclusions}

It is well know that surface water content and soil texture play very important role on dust emission. However, it is very difficult to measure the surface soil water content by nowadays technology and to know the soil texture when wind blows. In this paper, we assumed soil water content changes with depth linearly and used the relationship between DCI and dust emission so that we got the results. By using Shao's scheme and observed data in Dunhuang on April 13, 2002, vertical dust flux $F$ for different soil water content $(w)$ in the gobi desert and cropland are simulated and some of the results are shown in Table 3 and Fig. 5. It is clear that using Shao's model, there will be no dust emission when soil water content reaches to about 0.3 which was the mean value of soil water content at $20 \mathrm{~cm}$ for the cropland during spring of 2002 and there do have dust emission (Du et al. 2002b). For the gobi desert, when $w$ is the same as that in oasis, $F$ would be only about $1 / 10000$ of that in oasis. When $w$ is larger than 0.3 , there will be no dust emission from the gobi desert either. As shown in Fig. 5, dust emission is too difficult to occur when cropland surface soil is hard. However, for the same cropland, when surface becomes loose by agricultural activities such as spring ploughing, dust emission will become much easier and its amount will be hundreds of times larger than that from the gobi desert.

On the basis of the analyses mentioned above, the following conclusions can be obtained: 
(1) For cropland in arid area, when there is no influence of agricultural activities such as ploughing, due to the higher surface soil water content in it than that in the gobi desert, threshold friction velocity will be larger, too. For the cropland in Dunhuang it was $0.35 \mathrm{~ms}^{-1}$ in April of 2002 by Shao's equation, which was larger than that in the gobi desert $\left(0.24 \mathrm{~ms}^{-1}\right.$ by observation and $0.31 \mathrm{~ms}^{-1}$ by Shao's equation). Therefore, dust emission in such cropland is more difficult than that in the gobi desert.

(2) For a just ploughed cropland, hard layer of the surface soil is destroyed entirely and threshold friction velocity will be decreased greatly. In Dunhuang oasis, it decreased from $0.35 \mathrm{~ms}^{-1}$ to about $0.20 \mathrm{~ms}^{-1}$, even less than that in the gobi desert, and the dust emission rate in such cropland is hundreds of times larger than that in the gobi desert.

In addition, as mentioned above, in the dust emission model of Shao (2001), the influences of surface soil hardness and human (agricultural) activities are not considered enough. In this paper, we tried to research these questions and got some useful conclusions. However, due to the limit of observed data, only two soil types near the observation sites in Dunhuang are researched, which is not enough obviously. In the future, more efforts will be put into the effects of surface soil hardness and human (agricultural) activities on dust emission. If the empirical or theoretical functions of these two factors could be solved, the dust emission model would be improved.

\section{Acknowledgments}

The present study was carried out as a part of the Sino-Japanese Cooperation Program ADEC supported by Chinese Academy of Sciences and Japan Ministry of Education, Culture, Sports, Science and Technology. The authors wish to thank Prof. Yaping Shao for offering the dust emission model. Also, this research was supported by grants from National Natural Science Foundation of China (40375042).

\section{References}

Cheng, T. and Z. Shen, 2002: The Radiative Forcing of Atmospheric Dust in Northwest China. Plateau Meteorology, 21, 471-478.

Dong, G., C. Li, J. Jin, S. Gao, and D. Wu, 1987: Some Results about Wind Tunnel Experiment for Wind Erosion. Chinese Science Bulletin, 32, 297-301.

Du, M., S. Yonemura, Z. Shen, Y. Shen, W. Wang, and T. Maki, 2002a: Wind erosion processes during dust storm in Dunhuang, China. 624629. In: Gao, A. et al. (Eds.), 2002: Proceedings, 12th international soil conservation organization conference, May 26-31, 2002 Beijing, China, Vol. IV, Tsinghua University Press, 656pp. , - - T. Maki, Y. Yamada, Z. Shen, Y. Shen, W. Wang, S. Kawashima, and S. Inoue, 2002b: Characteristics of dust emission at farmland in Dunhuang, China. Earth Environment, 7, 187-195.

Dyer, A.J. and B.B. Hicks, 1970: Flux Gradient transport of heat and water in an unstable atmosphere. Quart. J. Roy. Meteor. Soc., 93, 501508.

Fecan, F., B. Marticorena, and G. Bergametti, 1999: Parameterization of the increase of the aeolian erosion threshold wind friction velocity due to soil moisture for arid and semi-arid areas. Ann. Geophys., 17, 149-157.

Raupach, M.R., 1993: Dry deposition of gases and particles to vegetation. Clean Air, 27, 200-203.

Shao, Y., 2001: A model for mineral dust emission. J. Geophys. Res., 106, 20239-20254. - and M.L. Lance, 1997: Wind erosion prediction over the Australian continent. J. Geophys. Res., 102, 30091-30105.

and H. Lu, 2000: A simple expression for wind erosion threshold friction velocity. $J$. Geophys. Res., 105, 22437-22443.

, Y. Yang, J. Wang, Z. Song, M.L. Lance, C. Dong, Z. Zhang, Z. Lin, Y. Kanai, S. Yabuki, and Y. Chun, 2003: Northeast Asian dust storms: Real-time numerical prediction and validation. J. Geophys. Res., 102, 30091-30105.

Shen, Y., Z. Shen, M. Du, and W. Wang, 2003: Variational Characteristics of Some Parameters and Factors during Dusty Weather in Spring of Dunhuang. Plateau Meteorology, 22, 378-384.

Zhang, H., R. Li, T. Zhang, Y. Li, and Y. Su, 2002: Field Observations of Wind Erosion Sediment in Bare Sandy Farm Land During ErosionProne Spring. J. Soil and Water Conservation, 16, 29-32.

Zhang, Q., X. Cao, G. Wei, and R. Huang, 2002: Bulk transfer coefficients of the atmospheric momentum and sensible heat over desert and Gobi in arid climate region of Northwest China. Science in China, 45(D), 468-480.

Zhang, X., R. Arimoto, and Z. An, 1997: Dust emission from Chinese desert source linked to variations in atmospheric circulation. J. Geophys. Res., 102, 28041-28047. 